\title{
The use of SPECT in preoperative assessment of patients with lung cancer
}

\author{
D.B. Piai*, R. Quagliatto Jr*, I. Toro\#, C. Cunha Neto", E. Etchbehere`, E. Camargo
}

The use of SPECT in preoperative assessment of patients with lung cancer. D. B. Piai, R. Quagliatto Jr, I. Toro, C. Cunha Neto, E. Etchbehere, E. Camargo. (C)ERS Journals Ltd 2004.

ABSTRACT: Perfusion scintigraphy is the most frequently used method for the regional assessment of pulmonary function in candidates for pulmonary resection with borderline respiratory function. This method provides two-dimensional images, and it considers all the segments of the pulmonary lobes as having the same volume and function, without considering the spatial overlapping of pulmonary areas with different function. As single-photon emission computed tomography (SPECT) provides tomographic imaging, this could be a more precise method for regional assessment.

In this study, the postoperative predicted forced expiratory volume in one second (FEV1) (FEV1,ppo) was calculated in 26 patients with lung cancer using FEV1, quantitative lung perfusion scan with planar acquisition (PA) and quantitative lung perfusion scan with tomographic imaging (SPECT).

The estimated FEV1,ppo values obtained using both methods were compared with FEV1 values measured after surgery (mean: $48 \pm 44$ days; range: $15-180$ days; median: 32 days). The Pearson's linear correlation coefficient was 0.8840 for FEV1,ppo estimated by PA and 0.8791 for FEV1,ppo estimated by SPECT. The linear correlation coefficient for lobectomy was greater than the coefficient for pneumonectomy using both methods.

In conclusion, both methods show good correlation for real postoperative pulmonary function without demonstrating single-photon emission computed tomography superiority over planar acquisition, and both methods were more effective for estimating postoperative predicted forced expiratory volume in one second in lobectomies than in pneumonectomies.

Eur Respir J 2004; 24: 258-262.
*Depts of Internal Medicine, and ${ }^{\#}$ Thoracic Surgery, and Service of Nuclear Medicine, State University of Campinas, Campinas, São Paulo, Brazil

Correspondence: D.B. Piai

Av. Independência, 2600

13416-230 - Piracicaba

São Paulo

Brazil

Fax: 551934341999

E-mail: dpiai@unipira.com.br

Keywords: Lung cancer preoperative assessment scintigraphy

single-photon emission computed tomography

Received: November 42003

Accepted after revision: March 312004
Surgical resection is the treatment of choice for nonsmall cell lung cancer, and this therapy should be encouraged, as the prognosis worsens for patients who are not operated on. However, the removal of the lung parenchyma in patients, the majority of whom are smokers, and who have compromised cardiovascular and lung conditions, may cause deterioration in ventilatory function and lead to cardiopulmonary failure or death. Therefore, in these patients, a preoperative assessment is extremely important before the appropriate therapy is chosen [1-4].

Pneumonectomy is well tolerated by the patient if: the forced expiratory volume in one second (FEV1) is either $\geqslant 2 \mathrm{~L}$ or $>60 \%$ FEV1 predicted; the maximal voluntary ventilation (MVV) is $>50 \%$ pred; the residual volume/total lung capacity ratio is either $<0.5$ or the carbon monoxide diffusion capacity of the lung is $>60 \%$. Lobectomy is well tolerated by the patient if: the FEV1 is $\geqslant 1 \mathrm{~L}$ and if the MVV is $\geqslant 40 \%$ pred. Nevertheless, many patients who could benefit from resection surgery show poor functional values that go against an indication for this surgery. In these cases other assessments are needed, such as perfusion or ventilation pulmonary scintigraphy, which are the most frequently used methods, as they provide a regional assessment of lung function and can be used to estimate postoperative pulmonary function, using the predicted postoperative FEV1 (FEV1,ppo) [5-13]. Operative risks in patients with FEV1,ppo $0.8-1.0 \mathrm{~L}$ or $>40 \%$ FEV1 pred are acceptable for indicating lung resection for both pneumonectomy and lobectomy [14-16].

Pulmonary scintigraphy with planar acquisition (PA) provides two-dimensional pulmonary images, and the estimated FEV1,ppo considers all the segments of the lung lobes as having the same volume and function, without considering the spatial overlapping of pulmonary areas with different functions, which could diminish the precision of the method. Conversely, single-photon emission computed tomography (SPECT) provides images that could help detect radioactivity in each pulmonary lobe, avoiding spatial overlapping, thus making the method of regional pulmonary function assessment more precise. In some hospitals, this method has been used to plan radiotherapy for lung application and also to monitor regional alterations of pulmonary function after radiotherapy in patients with extrapulmonary diseases [17-19].

The aim of the current study was to compare the effectiveness of both the PA and SPECT methods for estimating FEV1,ppo in patients with lung cancer during the preoperative period.

\section{Methods}

\section{Patients}

A prospective study was conducted on 26 patients with lung cancer, who underwent lung resection. The sample consisted 
of 23 males and three females; mean age $63 \pm 8.97 \mathrm{yrs}$ (table 1). This sample represented $70 \%$ of the patients who underwent this surgery during the period November 1998 to April 2001, at the Hospital de Clinicas (State University of Campinas, São Paulo, Brazil). All the patients were informed about the research protocol, which had received the approval of the hospital's Commission for Ethics in Research. All the patients underwent a pulmonary function test with measurements of the forced vital capacity (FVC) and FEV1 according to the norms of the American Thoracic Society [20]. They also underwent the PA and SPECT. After surgery, the pulmonary function test was repeated ( $48 \pm 44$ days; median: 32 days).

\section{Lung perfusion scintigraphy protocol}

Injection and acquisition. All the patients were submitted to a lung perfusion scintigraphy, which did not require prior preparation. The patients received an intravenous injection of $185 \mathrm{MBq}(5 \mathrm{mCi})$ macroaggregated albumin labelled with technetium-99 in the supine position. Five minutes after radiotracer injection, static images of the lungs with 500,000 counts were obtained in the anterior, posterior, oblique posterior and lateral projections. Only anterior and posterior projections were used for PA estimation of FEV1,ppo. This procedure was followed by $360^{\circ}$ tomographic imaging, taking one image in every $6^{\circ}$ for SPECT images.

Processing and analysis. Semi-quantitative analyses of planar and tomographic images were performed.

In the PA, regions of interest (ROI) were drawn in the anterior and posterior projections around the entire lung and also adjacent to the lungs, in order to subtract the background radiation. The percentage of the function of each lung was calculated by the geometric mean.

The SPECT images were normalised and reconstructed in sagittal planes. Ten sagittal images were generated for each lung. ROI were drawn, in each sagittal image, around the pulmonary lobes, according to their anatomical shape. The perfusion of each lobe was determined by the sum of the 10 ROI in the sagittal images. The per cent perfusion of each lobe was determined in relation to the perfusion of both lungs.

\section{Estimation of postoperative pulmonary function}

The FEV1,ppo values for each patient were estimated based on the preoperative FEV1 values, as well as the PA and SPECT pulmonary values. The values estimated by both methods were compared with the postoperative FEV1 values.

In PA, FEV1,ppo was estimated using different formulas for pneumonectomy and lobectomy. For pneumonectomy the formula below was used:

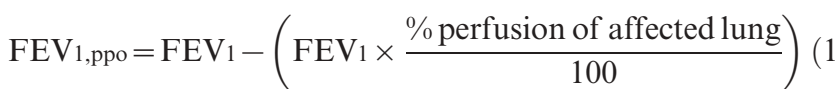

where $\%$ perfusion of affected lung is the percentage of perfusion of lung with tumour. For lobectomy the FEV1,ppo was estimated using the formula described by ALI et al. [21]:

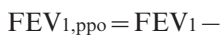

$\left(\mathrm{FEV}_{1} \times \frac{\% \text { perfusion of affected lung }}{100} \times \frac{\text { segments of affected lobe(s) }}{\text { segments of lung }}\right)(2)$ where segments of affected lobe(s) is the number of segments

Table 1.-Clinical and functional characteristics

\begin{tabular}{|c|c|c|c|c|c|c|c|c|c|c|c|c|}
\hline $\begin{array}{l}\text { Subject } \\
\text { no. }\end{array}$ & $\begin{array}{l}\text { Age } \\
\text { yrs }\end{array}$ & Sex & Race & $\begin{array}{l}\text { Histological } \\
\text { type }\end{array}$ & $\begin{array}{c}\text { Karnofsky } \\
\%\end{array}$ & FVC L & FVC $\%$ & FEV1 L & FEV1 \% & $\begin{array}{l}\text { FEV1/ } \\
\text { FVC }\end{array}$ & $\begin{array}{c}\mathrm{PO}_{2} \\
\mathrm{mmHg}\end{array}$ & $\begin{array}{l}\mathrm{PCO}_{2} \\
\mathrm{mmHg}\end{array}$ \\
\hline 1 & 63 & $\mathrm{M}$ & $\mathrm{NC}$ & Epidermoid & 90 & 3.92 & 113 & 2.80 & 114 & 0.71 & 73.3 & 32.3 \\
\hline 2 & 68 & M & $\mathrm{C}$ & Adenocarcinoma & 100 & 3.53 & 105 & 2.31 & 99 & 0.66 & 75.3 & 31.8 \\
\hline 3 & 46 & M & $\mathrm{NC}$ & Large cells & 90 & 3.22 & 90 & 2.36 & 86 & 0.73 & 84.3 & 30.8 \\
\hline 4 & 60 & M & $\mathrm{NC}$ & Epidermoid & 90 & 3.21 & 99 & 2.58 & 110 & 0.80 & 87.8 & 29.7 \\
\hline 5 & 67 & M & $\mathrm{C}$ & Adenocarcinoma & 90 & 3.83 & 84 & 2.82 & 90 & 0.73 & 80.3 & 38.9 \\
\hline 6 & 69 & M & $\mathrm{C}$ & Adenocarcinoma & 100 & 3.34 & 96 & 2.69 & 112 & 0.86 & 89.3 & 33.2 \\
\hline 7 & 72 & $\mathrm{M}$ & $\mathrm{C}$ & Epidermoid & 100 & 2.97 & 75 & 2.69 & 101 & 0.90 & 66.1 & 37.5 \\
\hline 8 & 67 & M & $\mathrm{C}$ & Large cells & 100 & 2.51 & 72 & 2.06 & 84 & 0.82 & 72.5 & 41.9 \\
\hline 9 & 77 & M & $\mathrm{C}$ & Epidermoid & 100 & 3.68 & 96 & 2.78 & 111 & 0.75 & 73.7 & 41.2 \\
\hline 10 & 79 & M & $\mathrm{C}$ & Epidermoid & 80 & 2.86 & 98 & 1.89 & 66 & 0.66 & 77.8 & 36.9 \\
\hline 11 & 59 & M & $\mathrm{C}$ & Epidermoid & 100 & 2.53 & 70 & 2.03 & 76 & 0.80 & 78.6 & 37.5 \\
\hline 12 & 60 & M & $\mathrm{C}$ & Epidermoid & 90 & 3.29 & 85 & 2.26 & 81 & 0.79 & 83.5 & 34.5 \\
\hline 13 & 61 & M & $\mathrm{C}$ & Epidermoid & 90 & 2.67 & 69 & 1.71 & 62 & 0.64 & 75.4 & 42.9 \\
\hline 14 & 66 & M & $\mathrm{C}$ & Adenocarcinoma & 100 & 3.13 & 83 & 2.49 & 94 & 0.80 & 67.7 & 37.2 \\
\hline 15 & 68 & M & $\mathrm{C}$ & Epidermoid & 90 & 1.86 & 61 & 1.23 & 57 & 0.66 & 63.4 & 32.5 \\
\hline 16 & 53 & $\mathrm{~F}$ & $\mathrm{C}$ & Adenocarcinoma & 100 & 2.65 & 87 & 2.40 & 105 & 0.90 & 75.4 & 38.0 \\
\hline 17 & 67 & $\mathrm{~F}$ & $\mathrm{C}$ & Adenocarcinoma & 100 & 2.39 & 71 & 1.62 & 70 & 0.70 & 80.0 & 33.0 \\
\hline 18 & 50 & M & $\mathrm{C}$ & Adenocarcinoma & 90 & 4.00 & 84 & 3.28 & 93 & 0.82 & 83.3 & 38.3 \\
\hline 19 & 69 & M & $\mathrm{C}$ & Nonsmall cells & 100 & 3.28 & 136 & 2.06 & 108 & 0.63 & 73.5 & 42.0 \\
\hline 20 & 70 & M & $\mathrm{C}$ & Nonsmall cells & 100 & 4.80 & 107 & 3.01 & 85 & 0.63 & 77.5 & 36.1 \\
\hline 21 & 60 & M & $\mathrm{C}$ & Epidermoid & 90 & 3.82 & 117 & 2.01 & 76 & 0.53 & 62.4 & 37.0 \\
\hline 22 & 73 & M & $\mathrm{C}$ & Nonsmall cells & 90 & 2.37 & 85 & 0.99 & 45 & 0.45 & 69.0 & 34.6 \\
\hline 23 & 43 & $\mathrm{~F}$ & $\mathrm{C}$ & Large cells & 80 & 2.30 & 84 & 1.93 & 82 & 0.84 & NA & NA \\
\hline 24 & 69 & M & $\mathrm{C}$ & Nonsmall cells & 80 & 2.81 & 73 & 2.69 & 87 & 0.93 & 74.4 & 34.0 \\
\hline 25 & 70 & M & $\mathrm{C}$ & Epidermoid & 80 & 2.67 & 87 & 2.13 & 88 & 0.80 & 54.2 & 43.9 \\
\hline 26 & 54 & M & $\mathrm{C}$ & Epidermoid & 70 & 1.87 & 45 & 1.07 & 32 & 0.57 & 74.6 & 34.6 \\
\hline Mean & 63.8 & & & & 92 & 3.06 & 80,2 & 2.26 & 85.1 & 0.74 & 74.9 & 36.4 \\
\hline SD & 8.97 & & & & 0.08 & 0.70 & 30.5 & 0.58 & 20.2 & 0.12 & 8.1 & 3.9 \\
\hline
\end{tabular}

FVC: forced vital capacity; FEV1: forced expiratory volume in one second; $P_{\mathrm{O}_{2}}$ : partial pressure of oxygen ; $P \mathrm{CO}_{2}$ : partial pressure of carbon dioxide; M: male; F: female; C: Caucasian; NC: non-Caucasian; NA: not available. kPa $\times 0.133=\mathrm{mmHg}$. 
in pulmonary lobe(s) to be resected and segments of lung is the whole number of segments of affected lung.

In SPECT, the same formula was used for the calculation of FEV1,ppo in pneumonectomy and lobectomy:

$$
\mathrm{FEV}_{1, \mathrm{ppo}}=\mathrm{FEV}_{1-}
$$

$$
\left(\mathrm{FEV}_{1} \times \% \text { perfusion of resected lobe }(\mathrm{s})\right)
$$

where $\%$ perfusion of resected lobe(s) is the percentage of perfusion of lobe(s) to be resected with regard to total radiation of both lungs.

\section{Statistical analysis}

The Pearson or the Spearman correlation coefficient was applied, according to its need to verify the concordance between two measures. Values approximately equal to 1 indicated concordance $[22,23]$.

\section{Results}

The study consisted of 26 patients with lung cancer, 13 of these patients $(50 \%)$ underwent lobectomy and 13 patients $(50 \%)$ underwent pneumonectomy. The study on six patients was not completed because one patient missed the follow-up and five patients died within 54 days of surgery (two of pneumonia, one of septic shock, one of acute myocardial infarct and one of stroke).

The mean PA-estimated FEV1,ppo was $1.73 \pm 0.55 \mathrm{~L}$ and the Pearson linear correlation coefficient of the postoperative FEV1 was $0.8840(\mathrm{p}<0.0001)$. The mean SPECT-estimated
Table 3.-Pearson's linear correlation coefficient for the variables below

\begin{tabular}{lcc}
\hline Variables & Coefficient & p-value \\
\hline FEV1,ppo PA×postoperative FEV1 & 0.8840 & $<0.0001$ \\
FEV1,ppo SPECT $\times$ postoperative FEV1 & 0.8791 & $<0.0001$ \\
FEV1,ppo PA×FEV1,ppo SPECT & 0.9751 & $<0.0001$ \\
\hline
\end{tabular}

FEV1,ppo: postoperative predicted forced expiratory volume in one second; FEV1: forced expiratory volume in one second; PA: planar acquisition; SPECT: quantitative lung perfusion scan with tomographic imaging.

value of FEV1, ppo was $1.73 \pm 0.53 \mathrm{~L}$ and the Pearson linear correlation coefficient of the postoperative FEV1 was 0.8791 , as shown in tables 2 and 3. There was no significant difference between FEV1, ppo values estimated by PA and FEV1,ppo values estimated by SPECT (table 3).

With regard to the type of surgery performed, the PAestimated FEV1,ppo in relation to postoperative FEV1 presented a linear correlation coefficient of $0.8818(\mathrm{p}=0.0003)$ for lobectomies and $0.6444(\mathrm{p}=0.0610)$ for pneumonectomies. The SPECT-estimated FEV1,ppo in relation to postoperative FEV1, presented a linear correlation coefficient of 0.8182 $(\mathrm{p}=0.0021)$ for lobectomies and $0.5021 \quad \mathrm{p}=0.1684)$ for pneumonectomies (table 4).

\section{Discussion}

Predicted postoperative pulmonary function improves with the use of perfusion-ventilation lung scintigraphy. It shows a

\begin{tabular}{|c|c|c|c|c|}
\hline \multirow[t]{2}{*}{ Subject no. } & \multirow[t]{2}{*}{ Surgery performed } & \multicolumn{2}{|c|}{ FEV1,ppo L } & \multirow[t]{2}{*}{ Postoperative FEV1 L } \\
\hline & & PA & SPECT & \\
\hline 1 & Lobectomy & 2.45 & 2.42 & 1.78 \\
\hline 2 & Lobectomy & 2.14 & 1.85 & 1.91 \\
\hline 3 & Lobectomy & 2.00 & 2.22 & Death \\
\hline 4 & Pneumonectomy & 1.58 & 1.67 & 1.00 \\
\hline 5 & Lobectomy & 2.51 & 2.41 & 2.39 \\
\hline 6 & Lobectomy & 2.59 & 2.57 & 2.1 \\
\hline 7 & Pneumonectomy & 2.42 & 2.26 & Death \\
\hline 8 & Pneumonectomy & 1.36 & 1.36 & 1.14 \\
\hline 9 & Lobectomy & 2.39 & 2.37 & 1.96 \\
\hline 10 & Lobectomy & 1.61 & 1.54 & 1.26 \\
\hline 11 & Lobectomy & 1.32 & 1.29 & 1.44 \\
\hline 12 & Pneumonectomy & 1.44 & 1.64 & 1.51 \\
\hline 13 & Lobectomy & 1.43 & 1.41 & Death \\
\hline 14 & Lobectomy & 1.93 & 2.09 & 1.85 \\
\hline 15 & Pneumonectomy & 1.15 & 1.22 & 0.98 \\
\hline 16 & Pneumonectomy & 1.68 & 1.65 & 1.46 \\
\hline 17 & Pneumonectomy & 0.97 & 0.91 & Death \\
\hline 18 & Lobectomy & 2.77 & 2.67 & 2.24 \\
\hline 19 & Lobectomy & 1.80 & 1.66 & 1.22 \\
\hline 20 & Pneumonectomy & 1.62 & 1.62 & Death \\
\hline 21 & Pneumonectomy & 1.27 & 1.25 & 1.38 \\
\hline 22 & Lobectomy & 0.81 & 0.72 & 0.85 \\
\hline 23 & Pneumonectomy & 1.04 & 1.08 & 0.98 \\
\hline 24 & Pneumonectomy & 1.69 & 1.83 & NA \\
\hline 25 & Pneumonectomy & 1.87 & 2.09 & 1.83 \\
\hline 26 & Pneumonectomy & 1.18 & 1.18 & 1.47 \\
\hline Mean & & 1.73 & 1.73 & 1.54 \\
\hline SD & & 0.55 & 0.53 & 0.45 \\
\hline
\end{tabular}

Table 2. - Predicted and real postoperative pulmonary function

FEV1,ppo: postoperative predicted forced expiratory volume in one second; FEV1: forced expiratory volume in one second; PA: planar acquisition; SPECT: quantitative lung perfusion scan with tomographic imaging; NA: not available. 
Table 4.-Spearman's linear correlation coefficient for the variables according to the type of surgery

\begin{tabular}{llr}
\hline Variables & & Coefficient (p-value) \\
\cline { 2 - 3 } & Lobectomy & Pneumonectomy \\
\hline FEV1,ppo PA×postoperative FEV1 & $0.8818(0.0003)$ & $0.6444(0.0610)$ \\
FEV1,ppo SPECT $\times$ postoperative FEV1 & $0.8182(0.0021)$ & $0.5021(0.1684)$ \\
FEV1,ppo PA×FEV1,ppo SPECT & $0.9780(<0.0001)$ & $0.9670(<0.0001)$ \\
\hline
\end{tabular}

FEV1,ppo: postoperative predicted forced expiratory volume in one second; FEV1: forced expiratory volume in one second; PA: planar acquisition; SPECT: quantitative lung perfusion scan with tomographic imaging.

good degree of accuracy, it is noninvasive and accessible. Patients with spirometric results that indicate intermediate or high risk for surgery should have their regional lung function assessed by this method. In these cases, the FEV1,ppo is estimated by a significant linear correlation $[6,9,11,13]$. This method could be made more precise by incorporating tomographic imaging.

This study demonstrates a good correlation between FEV1,ppo estimated for both PA as well as SPECT and the real postoperative FEV1. Both methods were more precise in predicting postoperative pulmonary function for lobectomies than for pneumonectomies (table 4).

The FEV1,ppo estimated by SPECT has been used in the preoperative assessment of patients with lung cancer and the results obtained have been similar to those obtained in this study. IMAEDA et al. [24] conducted a study on 33 patients and analysed the precision of SPECT with perfusion-inhalation in the prediction of postoperative pulmonary function. The SPECT sections were correlated with the computerised tomographic images of the thorax for better delimitation of the lobes to be resected. After a postoperative period of 3-6 months, the correlation between FEV1,ppo and FEV1 was found to be good, with a linear correlation coefficient of $0.80-0.87$, respectively [24].

In the PA-estimated FEV1,ppo, the calculation of the pulmonary function of each lobe is obtained using an anteroposterior projection on a two-dimensional image. It does not take into consideration the spatial overlapping of the pulmonary lobes and the differences in their size or perfusion. Conversely, in the case of the SPECT-estimated FEV1,ppo, these problems can be resolved by measuring the perfusion for each pulmonary lobe, hoping for a better correlation between FEV1,ppo and real postoperative FEV1. Although the SPECT estimate of FEV1,ppo utilises more sophisticated technological resources, this method was not superior to the PA estimate of FEV1,ppo in this study (linear correlation coefficient: 0.9751 ; $\mathrm{p}<0.0001)$. Perhaps the SPECT estimate of FEV1,ppo could be improved by combining these images with computerised tomography, which does not provide functional images of the lung, but provides precise anatomic information that could diminish the anatomic imprecision of the SPECT images [17-19].

In conclusion, the postoperative predicted forced expiratory volume in one second estimated by both methods, planar acquisition and single-photon emission computed tomography, has a good correlation with the real forced expiratory volume in one second, but it did not verify the superiority of single-photon emission computed tomography over planar acquisition. Both methods were more precise in patients who underwent a lobectomy than in those who underwent a pneumonectomy.

\section{References}

1. American Thoracic Society/European Respiratory Society. Pretreatment evaluation of non-small-cell lung cancer. Am J Respir Crit Care Med 1997; 156: 320-332.
2. Markos J, Mullan BP, Hillman DR, et al. Preoperative assessment as a predictor of mortality and morbidity after lung resection. Am Rev Respir Dis 1989; 139: 902-910.

3. Bolliger CT, Jordan P, Solèr M, et al. Pulmonary function and exercise capacity after lung ressection. Eur Respir J 1996; 9: 415-421.

4. Crook A, Duffy A, Girling DJ, Souhami RL, Parmar MKB. Survey on the treatment of non-small cell lung cancer (NSCLC) in England and Wales. Eur Respir J 1997; 10: $1552-1558$.

5. Larsen KR, Svendsen UG, Milman N, Brenoe J, Petersen $\mathrm{BN}$. Exercise testing in the preoperative evaluation of patients with bronchogenic carcinoma. Eur Respir J 1997; 10: $1559-1565$.

6. Dunn WF, Scanlon PD. Preoperative pulmonary function testing for patients with lung cancer. Mayo Clin Proc 1993; 68: $371-377$.

7. Block AJ, Olsen GN. Preoperative pulmonary function testing. JAMA 1976; 235: 257-258.

8. Miller JI. Physiologic evaluation of pulmonary function in the candidate for lung resection. J Thorac Cardiovasc Surg 1993; 105: 347-352.

9. Corris PA, Ellis DA, Hawkins T, Gibson GJ. Use of radionuclide scanning in the preoperative estimation of pulmonar function ofter pneumonectomy. Thorax 1987; 42: 285-291.

10. Wernly JA, DeMeester TR, Kirchner PT, Myerowitz PD, Oxford DE, Golomb HM. Clinical value of quantitative ventilation-perfusion lung scans in the surgical management of bronchogenic carcinoma. J Thorac Cardiovasc Surg 1980; 80: 535-543.

11. Izquierdo JM, Pac JJ, Casanova J, et al. Cirugía resectiva pulmonar en pacientes en el límite funcional. Arch Bronconeumol 1995; 31: 328-332.

12. Wagner HN. The use of radioisotope techniques for the evaluation of patients with pulmonary disease. Am Rev Respir Dis 1976; 113: 203-218.

13. Schirren J, Krysa S, Trainer S, Drings P, Vogt-Moykopf I. Surgical treatment and results. In: Spiro SG, ed. Carcinoma of the lung. Eur Respir Mon 1995, 1: 1, 212-240.

14. Olsen GN, Block AJ, Swenson EW, Castle JR, Wynne JW. Pulmonary function evaluation of the lung resection candidate: a prospective study. Am Rev Respir Dis 1975; 111: 379-387.

15. Pretreatment evaluation of non-small cell lung cancer. American Thoracic Society/European Respiratory Society. Am J Respir Crit Care Med 1997; 156: 320-332.

16. Bolliger CT, Perruchoud AP. Functional evaluation of the lung resection candidate. Eur Respir J 1998; 11: 198-212.

17. Boersma LJ, Damen EMF, de Boer RW. A new method to determine dose-effect relations for local lung-function change using correlated SPECT and CT data. Radiother Oncol 1993; 29: 110-116.

18. Damen EMF, Muller SH, Boersma LJ, Boer RW, Lebesque JV. Quantifying local lung perfusion and ventilation using correlated SPECT and CT data. J Nucl Med 1994; 35: 784792.

19. Kwa SLS, Theuws JCM, Damen EMF, et al. Automatic three-dimensional matching of CT-SPECT and CT-CT to 
localize lung damage after radiotherapy. J Nucl Med 1998; 39: 1074-1080.

20. American Thoracic Society. Standardization of spirometry 1987 update. Am Rev Respir Dis 1987; 136: 1285-1298.

21. Ali MK, Mountain CF, Ewer MS, Johnston D, Haynie TP. Predicting loss of pulmonary function after pulmonary resection for bronchogenic carcinoma. Chest 1980; 77: 337342.
22. Agrest A, Finlay B. Statistical Methods for the Social Sciences. San Francisco, Dellen Publishing Company, 1986. 23. Conover WJ. Practical Nonparametric Statistics. New York, John Wiley \& Sons Inc., 1971.

24. Imaeda $\mathrm{T}$, Kanematsu $\mathrm{M}$, Asada $\mathrm{S}$, et al. Prediction of pulmonary function after resection of primary lung cancer utility of inhalation-perfusion SPECT imaging. Clin Nucl Med 1995; 20: 792-799. 